NBER WORKING PAPER SERIES

\title{
MISSALLOCATION AND FINANCIAL FRICTIONS: \\ SOME DIRECT EVIDENCE FROM THE DISPERSION IN BORROWING COSTS
}

\author{
Simon Gilchrist \\ Jae W. Sim \\ Egon Zakrajšek \\ Working Paper 18550 \\ http://www.nber.org/papers/w18550 \\ NATIONAL BUREAU OF ECONOMIC RESEARCH \\ 1050 Massachusetts Avenue \\ Cambridge, MA 02138 \\ November 2012
}

We thank participants at the RED Mini-Conference on "Misallocation and Productivity" (which took place at the 2011 SED Annual Meetings) for helpful comments. We are also grateful to Benjamin Moll, Diego Restuccia (the Guest Editor), Richard Rogerson, and two anonymous referees for numerous insightful comments and suggestions. Samuel Haltenhof and Ben Rump provided excellent research assistance. All errors and omissions are our own responsibility alone. The views expressed in this paper are solely the responsibility of the authors and should not be interpreted as reflecting the views of the Board of Governors of the Federal Reserve System, anyone else associated with the Federal Reserve System, or the National Bureau of Economic Research.

NBER working papers are circulated for discussion and comment purposes. They have not been peerreviewed or been subject to the review by the NBER Board of Directors that accompanies official NBER publications.

(C) 2012 by Simon Gilchrist, Jae W. Sim, and Egon Zakrajšek. All rights reserved. Short sections of text, not to exceed two paragraphs, may be quoted without explicit permission provided that full credit, including $(\odot$ notice, is given to the source. 
Missallocation and Financial Frictions: Some Direct Evidence From the Dispersion in Borrowing Costs

Simon Gilchrist, Jae W. Sim, and Egon Zakrajšek

NBER Working Paper No. 18550

November 2012

JEL No. D92,O16,O40

\begin{abstract}
Financial frictions distort the allocation of resources among productive units — all else equal, firms whose financing choices are affected by such frictions face higher borrowing costs than firms with ready access to capital markets. As a result, input choices may differ systematically across firms in ways that are unrelated to their productive efficiency. We propose an accounting framework that allows us to assess empirically the magnitude of the loss in aggregate resources due to such misallocation. To a second-order approximation, the framework requires only information on the dispersion in borrowing costs across firms, which we measure - for a subset of U.S. manufacturing firms - directly from the interest rate spreads on their outstanding publicly-traded debt. Given the observed dispersion in borrowing costs, our approximation method implies a relatively modest loss in efficiency due to resource misallocation-on the order of 1 to 2 percent of measured total factor productivity (TFP). In our framework, the correlation between firm size and borrowing costs has no bearing on TFP losses under the assumption that financial distortions and firm-level efficiency are jointly log-normally distributed. To take into account the effect of covariation between firm size and borrowing costs, we consider a more general framework, which dispenses with the assumption of log-normality and which implies somewhat higher estimates of the resource losses - about 3.5 percent of measured TFP. Counterfactual experiments indicate that dispersion in borrowing costs must be an order of magnitude higher than that observed in the U.S. financial data, in order for misallocation - arising from financial distortions - to account for a significant fraction of measured TFP differentials across countries.
\end{abstract}

Simon Gilchrist

Department of Economics

Boston University

270 Bay State Road

Boston, MA 02215

and NBER

sgilchri@bu.edu

Jae W. Sim

Division of Research and Statistics

Federal Reserve Board

Washington, DC 20551

Tel: 202-452-2670

Jae.W.Sim@frb.gov
Egon Zakrajšek

Division of Monetary Affairs

Federal Reserve Board

20th Street \& Constitution Avenue, NW

Washington, D.C. 20551

egon.zakrajsek@frb.gov 


\section{Introduction}

Economists have long emphasized that distortions in the allocation of resources across heterogeneous firms can have large adverse effects on aggregate productivity and on the gains from trade (cf. Hopenhavn and Rogerson (1993), Guner. Ventura, and Xu (2008), and Hopenvahn (2011)). Similarly, Restuccia and Rogerson (2008) have argued that systematic and persistent differences in the allocation of resources across production units of varying productivity may be an important determinant of differences in income per capita across countries, a hypothesis that seems to be borne out by the data. For example, using detailed microdata on manufacturing establishments

in China and India, Hsieh and Klenow (2009) estimate that resource misallocation accounts for 30 to 60 percent of the difference between the total factor productivity (TFP) in U.S. manufacturing and the corresponding sectoral TFP in China and India 1

In light of the enormous differences in the depth and sophistication of financial markets between developed and developing countries, a large literature has long stressed the role of finance in economic development; see Matsuvama (2007) for a comprehensive review. More recently, Amaral and Quintin (2010), Greenwood, Sanchez, and Wang (2010, 2012), and Buera, Kaboski, and Shin (2011) have developed theoretical models, which show -in a quantitative sense - that a large portion of cross-country differences in TFP may attributable to resource misallocation arising from imperfect financial markets. In a recent paper, however, Midrigan and Xu (2010) challenge these findings, arguing that financial distortions can account for only a modest portion (on the order of 5 percent) of the difference in manufacturing TFP between Columbia and South Korea, the latter being a benchmark country with highly developed capital markets. Thus, the extent to which financial frictions lead to reductions in TFP through resource misallocation appears to be an open question.

Although the TFP accounting methodology developed by Hsieh and Klenow (2009) leads to a persuasive conclusion that large differences in manufacturing TFP between advanced and developing economies reflect the dispersion in marginal revenue products across heterogeneous plants, it also suggests that there are substantial measured TFP losses in U.S. manufacturing. At the same time, Hsieh and Klenow (2009) are careful to ascribe such losses to potential measurement error rather than to the underlying frictions hampering the process of allocation of resources across firms. This tension raises an important question regarding the extent to which measures of dispersion based on plant-level marginal revenue products paint an accurate picture of resource misallocation that can be attributed directly to financial frictions, as opposed to alternative sources of frictions such as policy-induced tax distortions; gaps between average and marginal products due to adjustment costs; fixed production costs; or other measurement-related issues.

In this paper, we address this tension by developing an alternative TFP accounting procedure,

\footnotetext{
${ }^{1}$ As shown by Klenow and Rodríguez-Clare (1997) and Hall and Jones (1999) differences in income per capita across countries are primarily accounted for by low TFP in poorer countries.
} 
which relies on direct measures of firms' borrowing costs to measure the implied resource misallocation caused by distortions in credit markets. Specifically, we develop an accounting framework in which observed differences in borrowing costs across firms can be mapped into measures of aggregate resource misallocation that may plausibly be attributed to financial market frictions. Using a log-normal approximation, we show that the extent of resource misallocation can be inferred from cross-industry or cross-country information on the dispersion of borrowing costs.

We apply our accounting framework to a panel of U.S. manufacturing firms drawn from the Compustat database. Despite fairly large and persistent differences in borrowing costs across firms, our estimates imply relatively modest losses in TFP due to resource misallocation-roughly on the order of 3.5 percent of TFP in the U.S. manufacturing sector. This finding is consistent with the recent work of Hopenyahn (2011), whose quantitative analysis also suggests modest TFP losses for economically plausible degrees of micro-level distortions.

Our results can be obtained directly from the log-normal approximation and information on the dispersion of interest rates across firms. Nonetheless, our methodology also allows us to relax the log-normal approximation and infer TFP losses using the joint distribution of sales and borrowing costs. We find that the estimated losses under this approach closely match those obtained under the assumption of log-normality. This finding demonstrates both the robustness of our results and its applicability to a broader environment where firm-level data on the joint distribution of sales and borrowing costs may not be readily available. We also compare the measured dispersion in the observed user cost of capital to the dispersion in the user cost inferred from the realized revenue products, an approach consistent with the methodology of Hsieh and Klenow (2009). We find that using the latter approach, the dispersion in the implied user cost overstates the degree of dispersion - and hence the degree of resource misallocation - by a factor of four, compared with an approach that uses data on actual borrowing costs.

In the wake of the recent financial crisis, research into business cycle fluctuations such as that of Gilchrist. Sim, and Zakrajšek (2011), Khan and Thomas (2011), and Arellano, Bai. and Kehoe (2012) has analyzed the importance of dispersion in productivity for resource misallocation in environments where firms face imperfect financial markets. Contributing to this vein of research, we document a significant increase in the overall dispersion in firms' borrowing costs over the past decade. Although our results indicate that the overall loss in measured TFP due to the dispersion in borrowing costs is relatively small, this secular increase in the dispersion of borrowing costs implies a reduction in the aggregate TFP growth on the order of 20 to 40 basis points per year over the 2000-10 period. This finding suggests that increased heterogeneity in access to external finance may indeed have important macroeconomic consequences, even in countries with well-developed financial markets such as the United States.

The road map for the remainder of the paper is as follows. In the next section, we present some basic facts regarding the dispersion in observed borrowing costs for our sample of U.S. man- 
ufacturing firms. In Section 3, we develop our accounting framework. Section 4 presents our main empirical results along with several robustness exercises. Section 5 concludes.

\section{Borrowing Costs and Firm Size: Some Some Stylized Facts}

In this section, we briefly describe our unique data set on firm-level borrowing costs and present some stylized facts about the relationship between the cross-sectional dispersion in borrowing costs and firm size.

\subsection{Data Description}

Our main analysis focuses on a subset of U.S. manufacturing corporations. The distinguishing characteristic of these firms is that they have access to the corporate bond market. For a panel of such firms covered by the Standard \& Poor's (S\&P) Compustat and the Center for Research in Security Prices (CRSP), we obtained month-end secondary market prices of their outstanding securities from the Lehman/Warga and Merrill Lynch databases 2 By limiting the sample to senior unsecured issues with a fixed coupon schedule, we ensure that external borrowing costs of different firms are measured at the same point in their capital structure.

Using the secondary market prices of individual securities, we construct the corresponding credit spreads - measured relative to risk-free Treasury rates - based on the methodology described

in Gilchrist and Zakrajšek (2012). To ensure that our results are not driven by a small number of extreme observations, we eliminated all observations with credit spreads below 5 basis points and greater than 1,000 basis points, cutoffs corresponding roughly to the 2.5 th and 97.5 th percentiles of the credit spread distribution, respectively. In addition, we eliminated from our sample very small corporate issues (par value of less than $\$ 1$ million) and all observations with a remaining term-tomaturity of less than one year or more than 30 years. These selection criteria yielded a sample of 2,623 individual securities over the 1985:M1-2010:M12 period. We matched these corporate securities with their issuer's quarterly income and balance sheet data from Compustat and daily data on equity valuations from CRSP, a procedure that yielded a matched sample of 496 firms, split about equally between durable and nondurable goods manufacturing industries.

Table 1 contains summary statistics for the key characteristics of bonds in our sample. Note that a typical firm in our sample has only a few senior unsecured issues outstanding at any point in time - the median firm, for example, has two such issues trading in any given month. This distribution, however, exhibits a significant positive skew, as some firms can have many more issues trading in the secondary market at a point in time. To calculate a firm-specific credit spread in any given month, we simply average the spreads on the firm's outstanding bonds in that month. 3

\footnotetext{
${ }^{2}$ These two proprietary data sources include secondary market prices for a vast majority of dollar-denominated bonds publicly issued in the U.S. corporate cash market; see Gilchrist, Yankov, and Zakrajšek (2009) for details.

${ }^{3}$ As a robustness check, we also computed firm-specific spreads as a weighted average of credit spreads on the
} 
Table 1: Selected Corporate Bond Characteristics

\begin{tabular}{lccccc}
\hline \hline Variable & Mean & SD & Min & P50 & Max \\
\hline No. of bonds per firm/month & 2.86 & 3.04 & 1.00 & 2.00 & 52.0 \\
Mkt. value of issue (\$mil.) & 358.9 & 360.1 & 1.22 & 260.4 & 5,628 \\
Maturity at issue (yrs.) & 12.8 & 9.2 & 1.0 & 10.0 & 40.0 \\
Term to maturity (yrs.) & 10.8 & 8.5 & 1.0 & 7.7 & 30.0 \\
Duration (years) & 6.42 & 3.36 & 0.92 & 5.92 & 15.8 \\
Credit rating (S\&P) & - & - & $\mathrm{D}$ & $\mathrm{A} 3$ & $\mathrm{AAA}$ \\
Coupon rate (pct.) & 7.06 & 1.97 & 1.70 & 6.85 & 15.25 \\
Nominal effective yield (pct.) & 6.80 & 2.20 & 0.46 & 6.71 & 19.89 \\
Credit spread (bps.) & 170 & 157 & 5 & 116 & 1,000 \\
\hline \hline
\end{tabular}

Note: Sample period: 1985:M1-2010:M12; Obs. =141,770; No. of bonds = 2,623; No. of firms $=496$.

Sample statistics are based on trimmed data (see text for details).

${ }^{\mathrm{a}}$ Market value of the outstanding issue deflated by the CPI $(2005=100)$.

The distribution of the market values of these issues is similarly skewed, with the range running from $\$ 1.2$ million to more than $\$ 5.6$ billion. The maturity of these debt instruments is fairly long, with the average maturity at issue of almost 13 years; the average remaining term-to-maturity in our sample is 10.84 years. In terms of default risk - at least as measured by the S\&P credit ratings - our sample spans the entire spectrum of credit quality, from "single D" to "triple A." At "A3," however, the median observation is still solidly in the investment-grade category. An average bond has an expected return of 170 basis points above the comparable risk-free rate, while the standard deviation of 157 basis points reflects the wide range of credit quality in our sample.

We focus on the 1985-2010 period because it is characterized by a growing tendency for U.S. corporate borrowing to take the form of negotiable securities issued directly in capital markets. The resulting deepening of the corporate bond market has led to a substantial degree of disintermediation, as well as to the development of well-functioning markets in derivatives, in which credit, interest rate, and currency risks, for example, can be readily hedged.

A full-fledged corporate bond market tends to be also associated with sound financial reporting systems, a thriving community of professional financial analysts, multiple credit rating agencies, a wide range of corporate debt instruments demanding sophisticated credit analysis, and efficient procedures for corporate reorganization and liquidation, factors that greatly facilitate the process of price discovery for corporate debt claims 4 Indeed, a well-developed corporate bond market is in a much better position than the banking system - which is heavily leveraged and subject to regulatory imperfections - to exert a crucial disciplinary role exercised by market forces 5 As

firm's outstanding bonds, with weights equal to the market value of each issue. This alternative weighting procedure had no effect on any of the results reported in the paper.

${ }^{4}$ For example, using high-frequency bond transaction prices of U.S. firms, Hotchkiss and Ronen (2002) find that the informational efficiency of corporate bond prices is similar to that of the underlying stocks.

${ }^{5}$ As shown by the theoretical work of Hakansson (1982), the financial system with a well-developed bond market will-under fairly general conditions - Pareto-dominate a financial system in which banks do most of the lending. 
Figure 1: Growth of Real Sales in U.S. Manufacturing

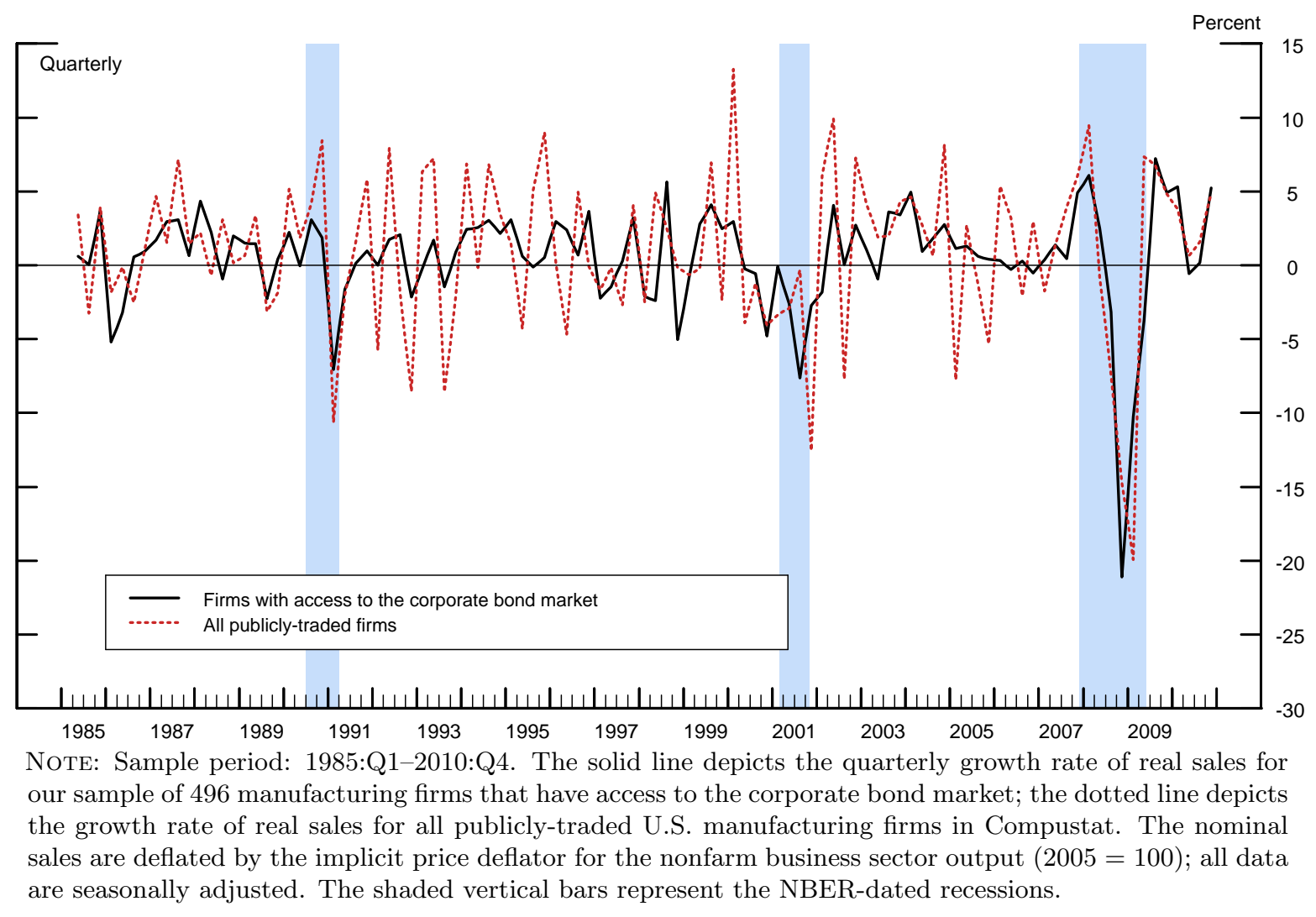

a result, the variation in our firm-specific interest rates likely reflects the dispersion in "true" borrowing costs both across firms and over time 6

Although our sample is restricted to manufacturing firms with the access to the corporate bond market, these 496 firms account, on average, for about 50 percent of total sales in U.S. manufacturing over the 1985-2010 period. Moreover, as shown in Figure1, the cyclical fluctuations in their sales closely match the growth of sales of all publicly-traded manufacturing firms in the Compustat database. In combination with the fact that our sample of firms spans a wide range of credit quality (see Table 1), these features of the data suggest that the dispersion in borrowing costs for this subset of firms is likely representative of the manufacturing sector as a whole.

\footnotetext{
${ }^{6}$ In fact, Gilchrist and Zakraišek (2007) use such firm-specific interest rates to construct the user cost of capital for a large panel of U.S. nonfinancial firms. According to their results, investment spending is highly responsive to fluctuations in the user cost of capital that utilizes firm-specific interest rates; moreover, their estimates of the long-run elasticity of capital with respect to the user costs are very close to unity, a result consistent with the Cobb-Douglas production technology.
} 


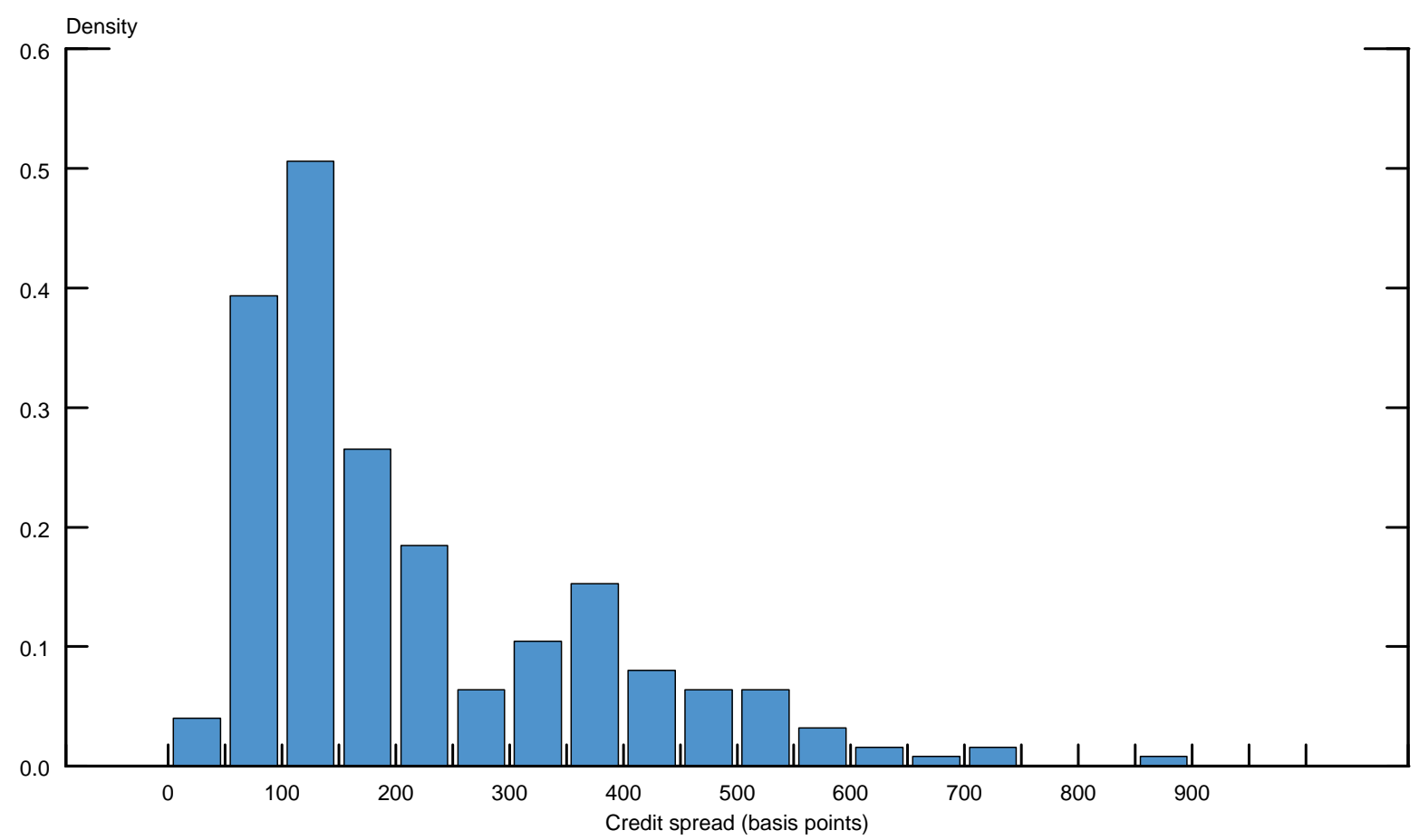

Note: The histogram depicts the distribution of firm-specific average credit spreads for our sample of 496 manufacturing firms.

\subsection{Firm-Level Borrowing Costs and Firm Size}

To get a sense of the cross-sectional dispersion in firm-level borrowing costs, we calculate the average credit spread for each firm over time, a measure of debt financing costs that abstracts from the substantial cyclical variation that characterizes credit spreads at business cycle frequencies. The resulting distribution is shown in Figure 2, The central tendency of the distribution - as measured by its mean - is 240 basis points, while its standard deviation is about 160 basis points. Recall that this specific sample trims the upper tail of the distribution of credit spreads at 1,000 basis points, so the standard deviation of 160 basis points likely underestimates the true dispersion of credit spreads in the U.S. manufacturing sector.

To the extent that distortions in credit markets arising from agency conflicts between borrowers and lenders - as evidenced by the persistent dispersion in credit spreads - influence the firms' optimal input choices, we expect to see a negative relationship between firm size and credit spreads. In Figure 3, we plot the average credit spread for each firm over time against the average firm size as measured by real sales; the solid line shows the fitted values from regressing the firm-specific average credit spread on a second-order polynomial function of the logarithm of real sales. The fact 
Figure 3: Firm-Level Borrowing Costs and Firm Size

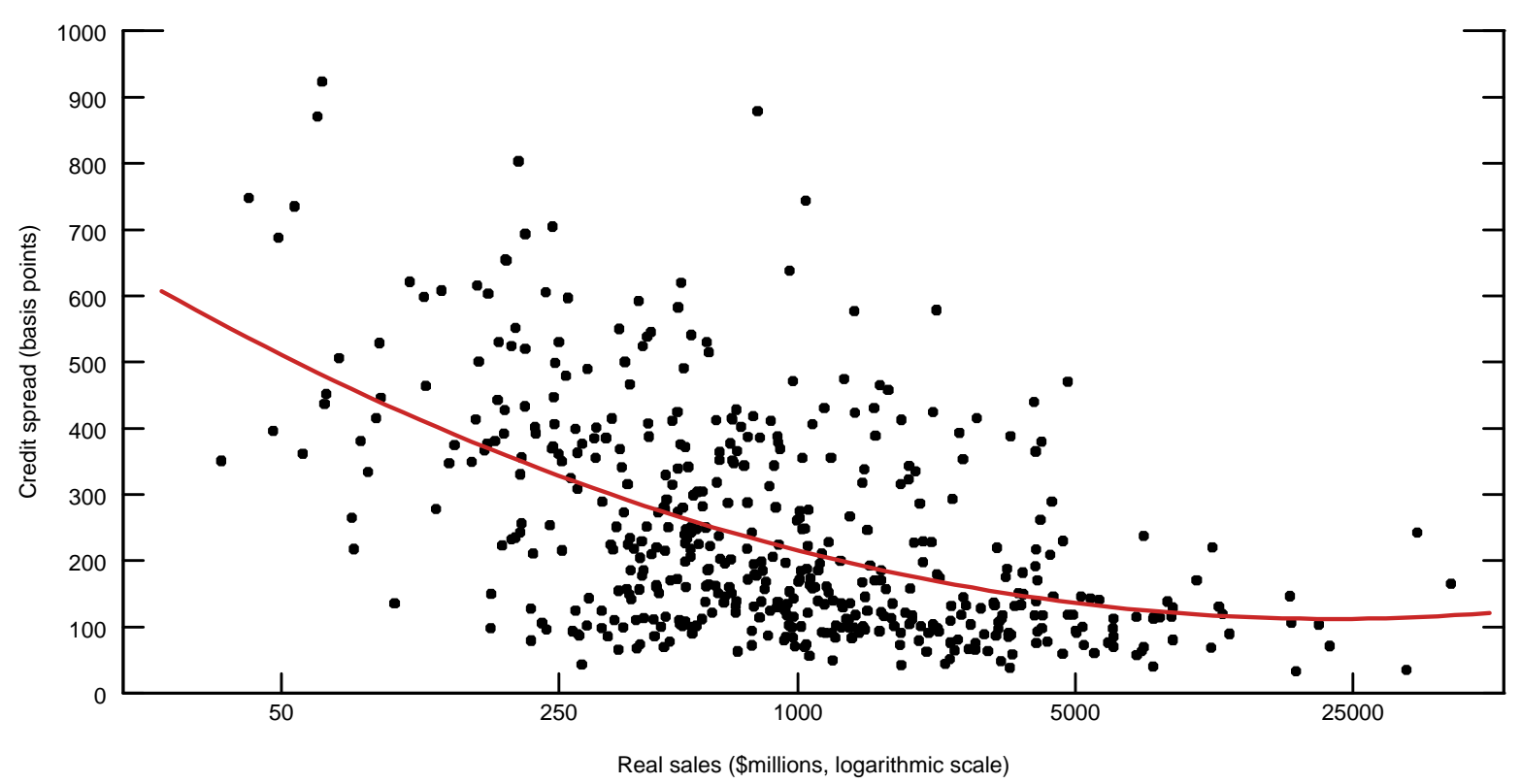

NotE: The scatter plot depicts the relationship between firm-specific average credit spreads and average firm size, as measured by real sales, for our sample of 496 manufacturing firms. The nominal sales are deflated by the implicit price deflator for the nonfarm business sector output $(2005=100)$.

that we are averaging over time implies that this relationship is capturing the long-term relationship between firm size and borrowing costs in the U.S. manufacturing sector. The strong negative relationship evident in the data is consistent with the notion that access to finance is an important determinant of the allocation of resources across firms.

As is well known, however, credit spreads capture both the likelihood of default and a residual component that relates to firm-specific factors such as loss given default and pricing terms reflecting individual firm characteristics 7 The likelihood of default is intimately related to leverage of the firm. Thus, to the extent that smaller firms are more leveraged, they will be considered by investors as being of lower credit quality and thus face higher spreads in the debt markets.

To control for differences in default risk across firms, we estimate the following regression:

$$
s_{i t}=\beta_{1} D D_{i t}+\beta_{2} D D_{i t}^{2}+\lambda_{t}+\epsilon_{i t},
$$

\footnotetext{
${ }^{7}$ In the corporate finance literature, there is a well-known result - the "credit spread puzzle" — which shows that less than one-half of the variation in corporate bond credit spreads can be attributed to the financial health of the issuer (e.g., Elton, Gruber, Agrawal, and Mann (2001)). As shown by Collin-Dufresne, Goldstein, and Martin (2001), Houwelling, Mentink, and Vorst (2005), Driessen (2005), and Duffie, Saita, and Wang (2007), the unexplained portion of the variation in credit spreads appears to reflect some combination of time-varying liquidity premium, to some extent the tax treatment of corporate bonds, and a default-risk factor.
} 
Figure 4: Residual Credit Spreads and Firm Size

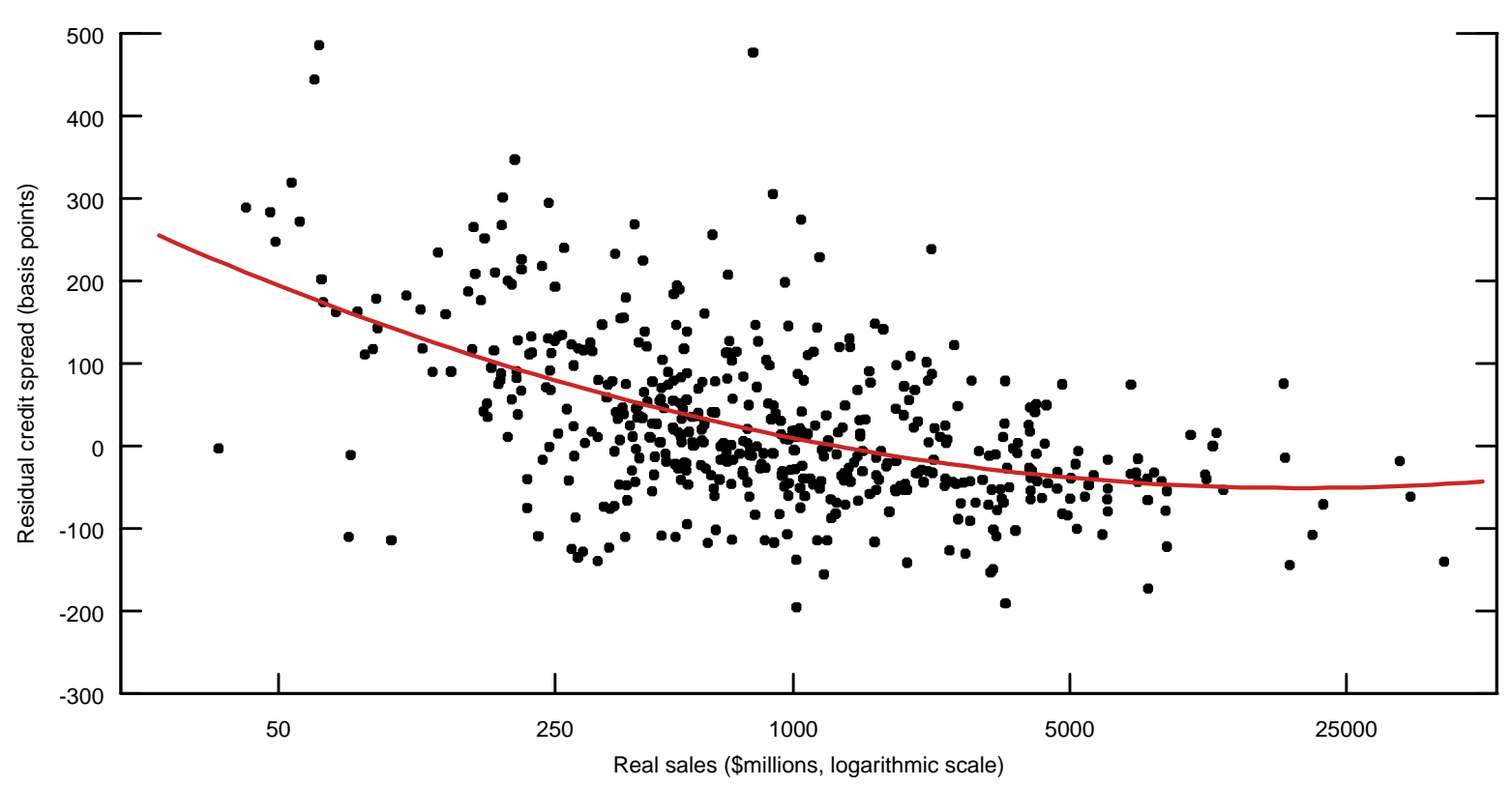

NotE: The scatter plot depicts the relationship between firm-specific average residual credit spreads and average firm size, as measured by real sales, for our sample of 496 manufacturing firms. The nominal sales are deflated by the implicit price deflator for the nonfarm business sector output $(2005=100)$.

where $s_{i t}$ denotes the credit spread of firm $i$ in month $t, D D_{i t}$ is the distance-to-default for firm $i$, and $\lambda_{t}$ is the time fixed effect that controls for common cyclical shocks. The key feature of the above specification is that the firm-specific (time-varying) default risk is captured by the distanceto-default (DD), a market-based indicator of credit risk based on the contingent claims framework developed in the seminal work of Merton (1974). Briefly, this option-theoretic approach assumes that a firm has just issued a single zero-coupon bond of face value $F$ that matures at date $T$. Rational stockholders will default at date $T$ only if the total value of the firm $V_{T}<F$; by assumption, the rights of the bondholders are activated only at the maturity date, as stockholders will maintain control of the firm even if the value of the firm $V_{s}<F$ for some $s<T$. Under the assumptions of the model, the probability of default - that is, $\operatorname{Pr}\left[V_{T}<F\right]$-depends on the distance-to-default, a volatility-adjusted measure of leverage inferred from equity valuations and the firm's observed capital structure 8

The regression fits the data quite well, explaining 55 percent of the variation in firm-specific credit spreads. In Figure 4, we plot the firm-specific average residual credit spread (i.e., $\frac{1}{T_{i}} \sum_{t=1}^{T_{i}} \hat{\epsilon}_{i t}$ )

\footnotetext{
${ }^{8}$ In addition to being used widely by the financial industry, our choice of the Merton DD-framework is also motivated by the work of Schaefer and Strebulaev (2008), who present compelling micro-level evidence showing that the DD-model accounts well for the default-risk component of corporate bond prices. To calculate the DDs for our sample of firms, we employ a robust procedure developed by Bharath and Shumway (2008).
} 
against the average firm size. Although the dispersion in credit spreads is reduced noticeably once default risk is taken into account, we nevertheless still find a strong negative relationship between the non-default component of credit spreads and firm size. Such permanent differences in borrowing costs across firms imply that financial distortions play a potentially important role in the misallocation of resources across firms.

\section{The TFP Accounting Framework}

In this section, we present the accounting framework that relates losses in TFP due to resource misallocation to dispersion in firm-specific borrowing costs. Our procedure is derived from the decreasing returns to scale production framework outlined in Midrigan and Xu (2010); it is also directly related to the TFP accounting procedure emphasized by Hsieh and Klenow (2009).

\subsection{The Production Environment}

We assume that firms (indexed by $i$ ) employing capital $(K)$ and labor $(L)$ have access to a decreasing returns to scale production function of the form:

$$
Y_{i}=A_{i}^{1-\eta}\left(K_{i}^{1-\alpha} L_{i}^{\alpha}\right)^{\eta}
$$

where $0<\eta<1$ is the degree of decreasing returns in production and $A_{i}$ is a firm-specific level of productivity 9 Decreasing returns may be due to the managerial span of control as in Lucas (1978) or, alternatively, due to monopolistic competition in an environment with Dixit-Stiglitz preferences over heterogeneous goods.

We further assume that firms must borrow at a firm-specific interest rate $r_{i}$ in order to obtain both capital and labor inputs. Letting $0<\delta<1$ denote the rate of capital depreciation and $W$ the aggregate wage, the optimal choice of inputs implies that firms equate the marginal revenue products of capital and labor to their respective costs:

$$
\begin{aligned}
(1-\alpha) \eta \frac{Y_{i}}{K_{i}} & =r_{i}+\delta \\
\alpha \eta \frac{Y_{i}}{L_{i}} & =\left(1+r_{i}\right) W
\end{aligned}
$$

where the second equation captures the fact that we assume that labor costs reflect borrowing costs as well as the aggregate wage.

\footnotetext{
${ }^{9}$ We interpret output as value added and assume that materials inputs enter the gross-output production function in a Leontief form; furthermore, we assume that firms do not face financing costs for materials inputs. We explore alternative production structures below.
} 
In this framework, the optimal capital-labor ratio is given by

$$
\frac{K_{i}}{L_{i}}=\frac{1-\alpha}{\alpha}\left[\frac{\left(1+r_{i}\right) W}{r_{i}+\delta}\right]
$$

Solving for the labor input yields

$$
\frac{\left[\left(1+r_{i}\right) W\right]}{\alpha \eta} L_{i}=A_{i}^{1-\eta}\left[\frac{1-\alpha}{\alpha}\left(\frac{\left(1+r_{i}\right) W}{r_{i}+\delta}\right) L_{i}\right]^{(1-\alpha) \eta} L_{i}^{\alpha \eta}
$$

which implies the optimal input choices:

$$
\begin{aligned}
L_{i} & =c_{L} A_{i}\left[\left(1+r_{i}\right)^{-\frac{1-(1-\alpha) \eta}{1-\eta}}\left(r_{i}+\delta\right)^{-\frac{(1-\alpha) \eta}{1-\eta}}\right] \\
K_{i} & =c_{K} A_{i}\left[\left(1+r_{i}\right)^{-\frac{\alpha \eta}{1-\eta}}\left(r_{i}+\delta\right)^{-\frac{1-\alpha \eta}{1-\eta}}\right]
\end{aligned}
$$

for some positive constants $c_{L}$ and $c_{K}$.

Letting

$$
\begin{aligned}
w_{i}^{l} & \equiv\left[\left(1+r_{i}\right)^{-\frac{1-(1-\alpha) \eta}{1-\eta}}\left(r_{i}+\delta\right)^{-\frac{(1-\alpha) \eta}{1-\eta}}\right] \\
w_{i}^{k} & \equiv\left[\left(1+r_{i}\right)^{-\frac{\alpha \eta}{1-\eta}}\left(r_{i}+\delta\right)^{-\frac{1-\alpha \eta}{1-\eta}}\right]
\end{aligned}
$$

then optimal input choices are proportional to firm-level productivity adjusted for firm-specific differences in factor input costs:

$$
\begin{aligned}
L_{i} & =c_{L} A_{i} w_{i}^{l} \\
K_{i} & =c_{K} A_{i} w_{i}^{k}
\end{aligned}
$$

In this context, $w_{i}^{l}$ and $w_{i}^{k}$ denote labor and capital "wedges," respectively, which induce distortions in input choices relative to an efficient allocation of inputs. The efficient allocation of inputs across firms is determined by setting $w_{i}^{l}=w^{l}$ and $w_{i}^{k}=w^{k}$ for all $i$.

\section{$3.2 \quad$ Aggregation and TFP}

Define aggregate labor and capital inputs according to

$$
L=c_{L} \int A_{i} w_{i}^{l} d i \quad \text { and } \quad K=c_{K} \int A_{i} w_{i}^{k} d i
$$

and define the wedge in the cost index as

$$
w_{i}=\left(w_{i}^{l}\right)^{\alpha}\left(w_{i}^{k}\right)^{1-\alpha}
$$


The aggregate output may then be expressed as

$$
Y=\int Y_{i} d i=c_{L}^{\alpha \eta} c_{K}^{(1-\alpha) \eta} \int A_{i} w_{i}^{\eta} d i
$$

Total factor productivity is measured as aggregate output relative to a geometrically-weighted average of aggregate labor and capital inputs:

$$
T F P=\frac{Y}{L^{\alpha \eta} K^{(1-\alpha) \eta}}=\frac{\int A_{i} w_{i}^{\eta} d i}{\left(\int A_{i} w_{i}^{l} d i\right)^{\alpha \eta}\left(\int A_{i} w_{i}^{k} d i\right)^{(1-\alpha) \eta}},
$$

or in logs,

$$
\log (T F P)=\log \left(\int A_{i} w_{i}^{\eta} d i\right)-\alpha \eta \log \left(\int A_{i} w_{i}^{l} d i\right)-(1-\alpha) \eta\left(\int A_{i} w_{i}^{k} d i\right)
$$

Assuming that $A_{i}, w_{i}^{l}$, and $w_{i}^{k}$ are jointly distributed according to a log-normal distribution,

$$
\left[\begin{array}{c}
\log A_{i} \\
\log w_{i}^{l} \\
\log w_{i}^{k}
\end{array}\right] \sim \operatorname{MVN}\left(\left[\begin{array}{c}
a \\
w_{l} \\
w_{k}
\end{array}\right],\left[\begin{array}{ccc}
\sigma_{a}^{2} & \sigma_{a, w_{l}} & \sigma_{a, w_{k}} \\
\sigma_{a, w_{l}} & \sigma_{w_{l}}^{2} & \sigma_{w_{l}, w_{k}} \\
\sigma_{a, w_{k}} & \sigma_{w_{l}, w_{k}}^{2} & \sigma_{w_{k}}^{2}
\end{array}\right]\right),
$$

then the second-order approximations of the three terms in equation (3) are given by

$$
\begin{aligned}
\log \left(\int A_{i} w_{i}^{\eta} d i\right)= & a+\eta\left[\alpha w_{l}+(1-\alpha) w_{k}\right]+\frac{\sigma_{a}^{2}}{2}+\frac{\eta^{2} \alpha^{2}}{2} \sigma_{w_{l}}^{2}+\frac{\eta^{2}(1-\alpha)^{2}}{2} \sigma_{w_{k}}^{2} \\
& +\eta^{2} \alpha(1-\alpha) \sigma_{w_{l}, w_{k}}+\eta\left[\alpha \sigma_{w_{l}, a}+(1-\alpha) \sigma_{w_{k}, a}\right] \\
\log \left(\int A_{i} w_{i}^{l} d i\right)= & a+w_{l}+\frac{\sigma_{a}^{2}}{2}+\frac{\sigma_{w_{l}}^{2}}{2}+\sigma_{w_{l}, a} ; \\
\log \left(\int A_{i} w_{i}^{k} d i\right)= & a+w_{k}+\frac{\sigma_{a}^{2}}{2}+\frac{\sigma_{w_{k}}^{2}}{2}+\sigma_{w_{k}, a} .
\end{aligned}
$$

Combining the above expressions and rearranging yields the second-order approximation of equation (3)

$$
\begin{aligned}
\log (T F P)= & (1-\eta)\left[a+\frac{\sigma_{a}^{2}}{2}\right]-\frac{\eta \alpha(1-\eta \alpha)}{2} \sigma_{w_{l}}^{2}-\frac{\eta(1-\alpha)[1-\eta(1-\alpha)]}{2} \sigma_{w_{k}}^{2} \\
& +\eta^{2} \alpha(1-\alpha) \operatorname{Corr}\left(w_{l}, w_{k}\right) \sigma_{w_{l}} \sigma_{w_{k}} .
\end{aligned}
$$

At this point, it is instructive to consider productivity gains that would arise from an efficient allocation of resources in an economy with heterogeneous production units. Specifically, consider a problem faced by a social planner, whose objective is to maximize aggregate output, subject to the constraint that aggregate labor and capital are equal to the amounts used in the economy with 
dispersion in input costs. Formally, this problem is given by

$$
Y_{E}=\max _{K_{i}, L_{i}} \int A_{i}^{1-\eta}\left(K_{i}^{1-\alpha} L_{i}^{\alpha}\right)^{\eta} d i
$$

subject to

$$
\int L_{i} d i=L \quad \text { and } \quad \int K_{i} d i=K
$$

Letting $\lambda_{L}$ and $\lambda_{K}$ denote the Lagrange multipliers on the aggregate input constraints, then optimal input choices imply constant factor input ratios across firms:

$$
(1-\alpha) \eta \frac{Y_{i}}{K_{i}}=\lambda_{K} \quad \text { and } \quad \alpha \eta \frac{Y_{i}}{L_{i}}=\lambda_{L}
$$

It is then straightforward to show that under this efficient allocation

$$
Y_{E}=\left(\int A_{i} d i\right)^{(1-\eta)} K^{(1-\alpha) \eta} L^{\alpha \eta},
$$

and the corresponding measure of TFP is given by

$$
T F P_{E}=\frac{Y_{E}}{K^{(1-\alpha) \eta} L^{\alpha \eta}}=\left(\int A_{i} d i\right)^{(1-\eta)} .
$$

In an economy with an efficient allocation of resources across heterogeneous production units, $w_{i}^{k}$ and $w_{i}^{l}$ are constant (i.e., $w_{i}^{l}=w^{l}$ and $w_{i}^{k}=w^{k}$ for all $i$ ). In those circumstances, the second-order approximation in equation (44) reduces to

$$
\log \left(T F P_{E}\right)=(1-\eta)\left[a+\frac{\sigma_{a}^{2}}{2}\right] .
$$

As the production environment in such an economy approaches constant returns-to-scale - that is, $\eta \rightarrow 1$ - the aggregate TFP is equal to $E\left[A_{i}\right]$, which is normalized to unity. With $0<\eta<1$, the above expression captures gains in economic efficiency arising solely from the benefits of dispersion in firm size in the diminishing returns-to-scale production environment.

The relative TFP loss that is solely attributable to resource misallocation caused by the dispersion in input costs is given by

$$
\begin{aligned}
\log \left(\frac{T F P_{E}}{T F P}\right)= & \frac{\eta \alpha(1-\eta \alpha)}{2} \sigma_{w_{l}}^{2}+\frac{\eta(1-\alpha)[1-\eta(1-\alpha)]}{2} \sigma_{w_{k}}^{2} \\
& -\eta^{2} \alpha(1-\alpha) \operatorname{Corr}\left(w_{l}, w_{k}\right) \sigma_{w_{l}} \sigma_{w_{k}} .
\end{aligned}
$$

Because aggregate inputs are held constant across the two allocations, the relative TFP loss is exactly equivalent to the relative loss in aggregate output due to the inefficient allocation of inputs 
implied by the presence of dispersion in input costs across firms.

Several comments about equation (5) are in order. First, this measure of TFP loss is an increasing function of the dispersion in the labor and capital wedges $\sigma_{w_{l}}$ and $\sigma_{w_{k}}$, respectively. Second, up to a second-order (log-normal) approximation, the covariance between firm-level TFP and the capital and labor wedges is irrelevant for the size - in percent terms - of the TFP loss due to misallocation 10 And lastly, holding dispersion in the labor and capital wedges fixed, a high correlation between the labor and capital wedges reduces the relative TFP loss due to resource misallocation.

To gain some intuition for this last point, it is helpful to express aggregate output and inputs as functions of the scale distortion $w_{i}$ and the distortion in the input mix $z_{i} \equiv \frac{K_{i}}{L_{i}}=\frac{w_{i}^{k}}{w_{i}^{l}}$. That is,

$$
Y=\int\left(A_{i} w_{i}\right)^{\eta} d i, \quad K=\int A_{i} w_{i} z_{i}^{\alpha} d i, \quad \text { and } \quad L=\int A_{i} w_{i} z_{i}^{(\alpha-1)} d i
$$

We can then attribute the relative TFP loss to distortions in scale - as measured by $\sigma_{w}^{2}$-and distortions in the input mix, as measured by $\sigma_{z}^{2}$ :

$$
\log \left(\frac{T F P_{E}}{T F P}\right)=\frac{\eta(1-\eta)}{2} \sigma_{w}^{2}+\frac{\eta \alpha(1-\alpha)}{2} \sigma_{z}^{2}
$$

where

$$
\begin{aligned}
\sigma_{w}^{2} & =\alpha^{2} \sigma_{w_{l}}^{2}+(1-\alpha)^{2} \sigma_{w_{k}}^{2}+2 \alpha(1-\alpha) \operatorname{Corr}\left(w_{l}, w_{k}\right) \sigma_{w_{l}} \sigma_{w_{k}} \\
\sigma_{z}^{2} & =\sigma_{w_{l}}^{2}+\sigma_{w_{k}}^{2}-2 \operatorname{Corr}\left(w_{l}, w_{k}\right) \sigma_{w_{l}} \sigma_{w_{k}} .
\end{aligned}
$$

In our framework, therefore, a high correlation between $w_{k}$ and $w_{l}$ is associated with increased scale distortion but less variation in the input mix across firms. On net, the efficiency gain from reduced variation in the input mix outweighs the efficiency loss owing to increased variation in firm size by the amount $\eta^{2} \alpha(1-\alpha) \operatorname{Corr}\left(w_{l}, w_{k}\right) \sigma_{w_{l}} \sigma_{w_{k}}$.

\subsection{Resource Misallocation and the Dispersion in Interest Rates}

To derive an approximate relationship between the dispersion in interest rates and TFP losses due to the misallocation of resources, we first consider a case in which both the labor and capital input choices are fully distorted by financial market frictions (i.e., capital input costs are $r_{i}+\delta$ and labor input costs are given by $\left(1+r_{i}\right) W$ ). In that case, $\operatorname{Corr}\left(w_{l}, w_{k}\right)=1$, and the log-labor and

\footnotetext{
${ }^{10}$ Note that up to a second-order approximation, this implies that in percent terms, size-based distortions matter to the extent that they create dispersion in the labor and capital wedges and not because they are based on size per se. Thus, distortions brought about by frictions in credit markets, government policies, and other institutional factors that influence the size distribution of firms, or that disproportionately distort the input mix across the size distribution, have a negative effect on TFP, precisely because they induce variation in the input wedges.
} 
log-capital wedges are given by

$$
\begin{aligned}
\log w_{i}^{l} & =-\frac{1-(1-\alpha) \eta}{1-\eta} \log \left(1+r_{i}\right)-\frac{(1-\alpha) \eta}{1-\eta} \log \left(r_{i}+\delta\right) \\
\log w_{i}^{k} & =-\frac{\alpha \eta}{1-\eta} \log \left(1+r_{i}\right)-\frac{1-\alpha \eta}{1-\eta} \log \left(r_{i}+\delta\right)
\end{aligned}
$$

The first-order approximations of the $\log$-wedges around $\log \left(r_{i}\right)$ are then given by

$$
\begin{aligned}
\log w_{i}^{l} & \approx-\frac{1}{1-\eta}\left[(1-(1-\alpha) \eta) \frac{r}{1+r}+(1-\alpha) \eta \frac{r}{r+\delta}\right] \log \left(r_{i}\right) \\
\log w_{i}^{k} & \approx-\frac{1}{1-\eta}\left[\alpha \eta \frac{r}{1+r}+(1-\alpha \eta) \frac{r}{r+\delta}\right] \log \left(r_{i}\right) .
\end{aligned}
$$

Thus, the ratio of the standard deviation of the labor wedge relative to the capital wedge can be approximated as

$$
\frac{\sigma_{w_{l}}}{\sigma_{w_{k}}} \approx \frac{[(1-(1-\alpha) \eta)(r+\delta)+(1-\alpha) \eta(1+r)]}{[\alpha \eta(r+\delta)+(1-\alpha \eta)(1+r)]}
$$

We can then approximate the relative TFP loss as

$$
\log \left(\frac{T F P_{E}}{T F P}\right)=\left[\frac{\eta(1-\alpha)[1-\eta(1-\alpha)]}{2}+\frac{\eta \alpha(1-\alpha \eta)}{2}\left(\frac{\sigma_{w_{l}}}{\sigma_{w_{k}}}\right)^{2}-\eta^{2} \alpha(1-\alpha) \frac{\sigma_{w_{l}}}{\sigma_{w_{k}}}\right] \sigma_{w_{k}}^{2},
$$

where

$$
\sigma_{w_{k}}=\frac{1}{1-\eta}\left[\alpha \eta \frac{r}{1+r}+(1-\alpha \eta) \frac{r}{r+\delta}\right] \sigma_{\log (r)} .
$$

The first term in equation (6) reflects the direct effect of variation in $w_{k}$ on the resource misallocation. The second term captures the direct effect of variation in $w_{l}$, while the third term is due to the covariance between $w_{l}$ and $w_{k}$.

Now, consider the case where financial market frictions induce firm-level variation in the usercost of capital $\left(r_{i}+\delta\right)$ but do not cause firm-level variation in labor input costs $(1+r) W$. In this case, the labor wedge $w_{l}$ varies across firms solely because of the induced variation in the capital-labor ratio. As a result,

$$
\frac{\sigma_{w_{l}}}{\sigma_{w_{k}}} \approx \frac{(1-\alpha) \eta}{1-\alpha \eta}
$$

and the relative TFP loss can be expressed as

$$
\log \left(\frac{T F P_{E}}{T F P}\right)=\left[\frac{\eta(1-\alpha)[1-\eta(1-\alpha)]}{2}-\frac{\eta \alpha(1-\alpha \eta)}{2}\left(\frac{\sigma_{w_{l}}}{\sigma_{w_{k}}}\right)^{2}\right] \sigma_{w_{k}}^{2}
$$

where

$$
\sigma_{w_{k}}=\left[\frac{(1-\alpha \eta)}{1-\eta}\right]\left[\frac{r}{r+\delta}\right] \sigma_{\log (r)} .
$$


Eliminating financial distortions in the labor market reduces the variability of the capital and labor wedges (i.e., $\sigma_{w_{k}}$ and $\sigma_{w_{k}}$ ) and, for chosen parameter values, leaves the ratio $\frac{\sigma_{w_{l}}}{\sigma_{w_{k}}}$ about unchanged. The negative sign in front of the second term in equation equation (77) reflects the fact that, on net, the labor-input distortion, as evidenced by $\sigma_{w_{l}}>0$, lowers the overall TFP loss by reducing the variation in the input mix across firms 11 As we show below, eliminating financial distortions in the labor market reduces TFP losses relative to the case where firms face borrowing constraints in both labor and capital markets.

\section{Results}

In this section, we use our framework to provide some estimates of TFP losses for the U.S. manufacturing sector implied by resource misallocation arising from financial market frictions. Specifically, we use the information on the dispersion of firm-specific borrowing costs to calculate the implied TFP loss, an approach that relies on the assumption of log-normality when computing the second-order approximation of the relative TFP loss. By utilizing the corresponding information on firm-level sales, we show that this approximation provides a reasonable estimate of TFP losses due to resource misallocation.

In our analysis, we assume that the firm-specific borrowing costs in quarter $t$ - denoted by $r_{i t}$ are equal to the real risk-free long-term interest rate $r_{t}^{*}$, augmented by the firm-specific premium given by the credit spread $s_{i t} 12$

$$
r_{i t}=r_{t}^{*}+s_{i t}
$$

For the real risk-free rate $r_{t}^{*}$, we use the difference between the 10-year nominal Treasury yield and the average expected CPI inflation over the next 10 years, as measured by the Philadelphia Fed's Survey of Professional Forecasters. In all exercises, we set the depreciation rate $\delta=0.06$, the labor share $\alpha=2 / 3$, and the degree of decreasing returns to scale $\eta=0.85$, values that are standard in the literature.

Figure 5 depicts the time-series evolution of the cross-sectional distribution of real interest rates for our sample of manufacturing firms with access to the corporate bond market. The shaded band around the median real interest rate (the solid line) depicts the 90th (P90) and 10th (P10) percentiles of the distribution of borrowing costs at each point in time. Over the 1985-2010 period, the P90-P10 range has fluctuated in the range between 140 basis and 670 basis points, an indication of a significant time-series variation in the dispersion of firm-level borrowing costs.

According to our accounting framework, we can infer $\log w_{i t}^{l}$ and $\log w_{i t}^{k}$ for each firm in our sample using equations (11) and (2) and the firm-specific real interest rate $r_{i t}$. Given these wedges,

\footnotetext{
${ }^{11}$ While this result is algebraically true for the case of no direct financial distortions in labor markets, numerical computations show that it also holds in the more general case.

${ }^{12}$ Quarterly credit spread $s_{i t}$ is calculated as a simple average of the corresponding monthly credit spreads.
} 
Figure 5: Dispersion of Firm-Level Borrowing Costs in U.S. Manufacturing

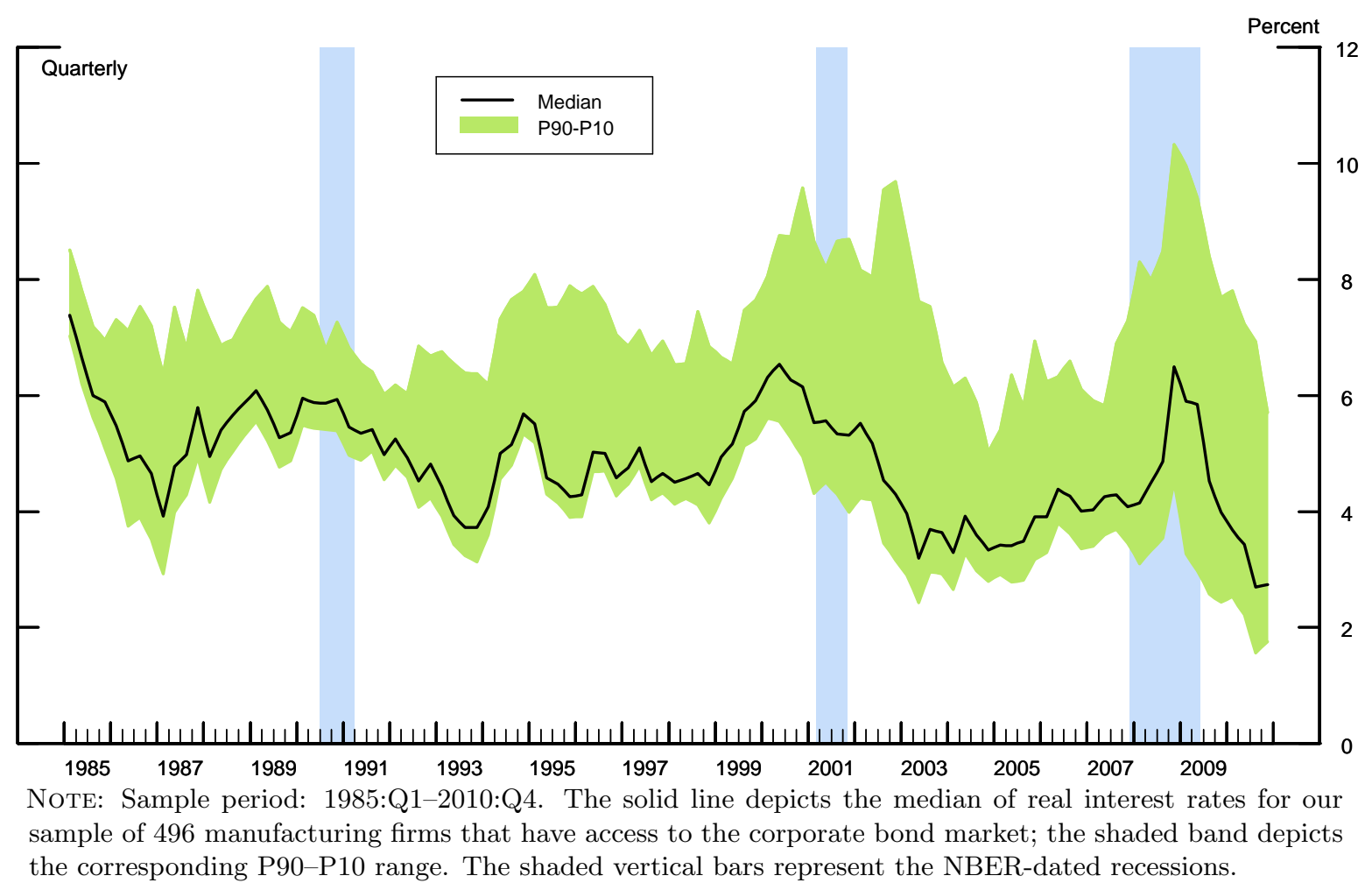

we can compute their respective standard deviations $\sigma_{w_{l}}$ and $\sigma_{w_{k}}$. Using equation (5), we can then calculate the implied TFP loss due to resource misallocation arising from financial market frictions.

The above procedure relies only on the dispersion in real interest rates to compute TFP losses due to resource misallocation. Given data on firm-level (real) sales - denoted by $Y_{i t}$-and firmspecific interest rates, it is possible to infer directly the implied capital and labor inputs, according to

$$
L_{i t}=\frac{\alpha \eta Y_{i t}}{\left(1+r_{i t}\right) W} \quad \text { and } \quad K_{i t}=\frac{(1-\alpha) \eta Y_{i t}}{r_{i t}+\delta} .
$$

Summing over sales and the implied inputs yields

$$
Y=\frac{1}{N T} \sum_{i} \sum_{t} Y_{i t}, \quad K=\frac{1}{N T} \sum_{i} \sum_{t} K_{i t}, \quad \text { and } \quad L=\frac{1}{N T} \sum_{i} \sum_{t} L_{i t},
$$

which allows us to calculate the implied aggregate TFP:

$$
T F P=\frac{Y}{(L)^{\alpha \eta}(K)^{(1-\alpha) \eta}} .
$$


To infer the level of aggregate TFP that would prevail in the case of the efficient allocation of resources, we first need to compute the firm-specific level of TFP using the relationship

$$
A_{i t}=\frac{Y_{i t}}{w_{i t}}
$$

where $w_{i t}=\left(w_{i t}^{l}\right)^{\alpha \eta}\left(w_{i t}^{k}\right)^{(1-\alpha) \eta}$ is the geometrically-weighted average of the labor and capital wedges. The efficient level of inputs $\left(K_{i t}^{E}, L_{i t}^{E}\right)$, along with the efficient level of output $Y_{i t}^{E}$, can be obtained using the relationships:

$$
K_{i t}^{E}=c_{K} A_{i t} \bar{w}^{k}, \quad L_{i t}^{E}=c_{L} A_{i t} \bar{w}^{l}, \quad \text { and } \quad Y_{i t}^{E}=A_{i t} / \bar{w}
$$

where $\bar{w}^{k}$ and $\bar{w}^{l}$ are the average capital and labor wedges observed in the data and $\bar{w}=\left(\bar{w}^{l}\right)^{\alpha}\left(\bar{w}^{k}\right)^{1-\alpha}$. Letting

$$
Y^{E}=\frac{1}{N T} \sum_{i} \sum_{t} Y_{i t}^{E}, \quad K^{E}=\frac{1}{N T} \sum_{i} \sum_{t} K_{i t}^{E}, \quad \text { and } \quad L^{E}=\frac{1}{N T} \sum_{i} \sum_{t} L_{i t}^{E}
$$

denote the aggregate output, capital, and labor that would be obtained under the efficient allocation of resources, the corresponding implied aggregate TFP - the level of TFP that would prevail in the absence of dispersion in borrowing costs - is given by

$$
T F P^{E}=\frac{Y^{E}}{\left(L^{E}\right)^{\alpha \eta}\left(K^{E}\right)^{(1-\alpha) \eta}}
$$

and the relative TFP loss due to resource misallocation by

$$
\text { Relative TFP Loss }=\log \left(\frac{T F P^{E}}{T F P}\right)
$$

Importantly, by using data on firm-specific sales and borrowing costs, we can infer the relative TFP loss due to resource misallocation without relying on the log-normal approximation. On the other hand, to the extent that there are significant nonfinancial distortions that influence firm size, the accounting procedure that relies on both borrowing costs and sales may, in fact, overstate the true loss in TFP that may be attributable to financial distortions. Thus, we view the log-normal approximation as a lower bound and the size-based measure as an upper bound to the potential TFP losses that may be attributed to resource misallocation brought about by frictions in credit markets.

The results of these two exercises are summarized in Table 2. We calculate the implied TFP losses for all 496 firms in our sample as well as for durable- and nondurable-goods producers separately. The entries under the heading "Approximate" are the implied TFP losses (in percent) calculated using only the dispersion in the firm-specific borrowing costs and rely on the log-normal 
Table 2: TFP Losses due to Resource Misallocation (Manufacturing Firms with Access to the Corporate Bond Market)

\begin{tabular}{|c|c|c|c|c|c|c|c|}
\hline \multirow[b]{2}{*}{ Sector } & \multirow[b]{2}{*}{$\bar{r}$} & \multirow[b]{2}{*}{$\sigma_{r}$} & \multirow[b]{2}{*}[r_{P10},r_{P90}]{} & \multirow[b]{2}{*}{$\sigma_{w_{l}}$} & \multirow[b]{2}{*}{$\sigma_{w_{k}}$} & \multicolumn{2}{|c|}{ Relative TFP Loss } \\
\hline & & & & & & Approximate & Actual \\
\hline All Manufacturing & 2.43 & 1.66 & {$[0.84,4.71]$} & 0.43 & 0.59 & $\begin{array}{c}1.75 \\
(1.40)\end{array}$ & $\begin{array}{c}3.44 \\
-\end{array}$ \\
\hline Durable Goods Mfg. & 2.62 & 1.69 & {$[0.92,4.99]$} & 0.43 & 0.60 & $\begin{array}{c}1.77 \\
(1.42)\end{array}$ & $\begin{array}{c}3.23 \\
-\end{array}$ \\
\hline Nondurable Goods Mfg. & 2.24 & 1.61 & {$[0.73,4.67]$} & 0.42 & 0.58 & $\begin{array}{c}1.69 \\
(1.36)\end{array}$ & $\begin{array}{c}3.63 \\
-\end{array}$ \\
\hline
\end{tabular}

Note: Sample period: 1985:Q1-2010:Q4; No. of firms = 496; Obs. = 16,975. Real interest rates and the implied TFP losses are in percent. The approximate TFP losses use only the information on the dispersion of firm-specific average real interest rates and rely on the second-order log-normal approximation; the approximate TFP losses reported in parentheses are calculated under the assumption that financial market frictions distort only the choice of the capital input. The actual TFP losses employ information on the firm-specific real interest rates and the corresponding real sales (see text for details).

approximation; the entries under the heading "Actual" are the implied TFP losses that employ information on both borrowing costs and sales. Columns labeled $\bar{r}, \sigma_{r}$, and $\left[r_{P 10}, r_{P 90}\right]$ contain the sample mean, the standard deviation, and the P90-P10 range, respectively, of the average firmspecific borrowing costs, while $\sigma_{w_{l}}$ and $\sigma_{w_{k}}$ denote the estimates of the cross-sectional standard deviation of the log labor and capital wedges used to compute the approximate TFP losses.

The results in Table 2 indicate that the loss in U.S. manufacturing TFP due to resource misallocation arising from financial market frictions is relatively modest. The losses implied by our approximation method are about 1.7 percent for the manufacturing sector as a whole and for its two main subsectors. As discussed in Section 3.3, the TFP loss in the model where financial frictions distort labor and capital input costs exceeds the loss in the model where financing frictions influence only the user cost of capital. In this latter case, the implied TFP loss for U.S. manufacturing, reported in parentheses, is 1.4 percent. Thus, financial frictions in both labor and capital markets imply only a modest increase in TFP losses relative to the model in which such frictions only influence the cost of capital inputs.

The actual TFP losses - that is, losses computed using the information on firm-specific borrowing costs and the corresponding sales - are around 3.5 percent for the manufacturing sector as a whole; as before, the estimated losses are highly comparable across the two subsectors. From an economic perspective, however, both methods imply TFP losses that are sufficiently close in magnitude, which suggests that the log-normal approximation provides a reasonable estimate of the TFP losses in the case where only information on the dispersion of borrowing costs across firms is available.

With these results in hand, we now consider the implications of two counterfactual scenarios, both of which assume greater dispersion in borrowing costs than actually observed in the U.S. data. 
Table 3: Counterfactual TFP Losses due to Resource Misallocation

\begin{tabular}{lcccccc}
\hline \hline Scenario & $\bar{r}$ & $\sigma_{r}$ & {$\left[r_{P 10}, r_{P 90}\right]$} & $\sigma_{w_{l}}$ & $\sigma_{w_{k}}$ & Loss \\
\hline S1: $r_{i t}=r_{t}^{*}+2 s_{i t}$ & 4.84 & 3.30 & {$[1.68,9.41]$} & 0.68 & 0.93 & 4.31 \\
& & & & & & $(3.26)$ \\
S2: $r_{i t}=r_{t}^{*}+10 s_{i t}$ & 24.2 & 16.5 & {$[8.38,46.7]$} & 1.57 & 1.95 & 19.9 \\
& & & & & & $(11.0)$ \\
\hline \hline
\end{tabular}

Note: Real interest rates and the implied TFP losses are in percent. The approximate TFP losses use only the information on the dispersion of firm-specific average real interest rates and rely on the second-order log-normal approximation; the approximate TFP losses reported in parentheses are calculated under the assumption that financial market frictions distort only the choice of the capital input.

In the first scenario, we assume that

$$
r_{i t}=r_{t}^{*}+2 s_{i t}
$$

which roughly doubles the dispersion in firm-level real interest rates; the second scenario counterfactually assumes that

$$
r_{i t}=r_{t}^{*}+10 s_{i t},
$$

which represents a ten-fold increase in the dispersion of borrowing costs.

As reported in the S1 row of Table 3, doubling the dispersion in firm-specific credit spreads implies an approximate loss in manufacturing TFP of 4.3 percent, assuming that financial market frictions distort the firm's choice of both the capital and labor inputs; assuming that financing constraints apply only to the capital input implies a TFP loss of about 3.3 percent. According to the S2 row, a ten-fold increase in the dispersion of firm-level borrowing costs implies a significant loss in TFP as a result of resource misallocation. Under this counterfactual scenario, the implied loss in TFP, according to our log-normal approximation, is almost 20 percent in the case in which borrowing constraints apply to both the labor market and the market for physical capital.

Note, however, that the ten-fold increase in credit spreads that underlies this counterfactual scenario implies an average real interest rate of almost 25 percent, with the P90-P10 range of 8.38 percent to 46.7 percent, an extremely high and disperse distribution of borrowing costs compared with the actual U.S. data. Indeed, one suspects that the first two moments of this counterfactual distribution are high even relative to the mean and dispersion in borrowing costs that one is likely to observe in developing economies, other than the very poor ones 13

\footnotetext{
${ }^{13}$ Measuring borrowing costs in developing economies, especially for countries that are in early stages of development, is complicated by the fact that a significant portion of credit to businesses and households is extended through informal sources (i.e., relatives, small shopkeepers, and money lenders). Nevertheless, the available evidence indicates that in the poorest countries, in addition to a very high average level of borrowing costs, there is a considerable degree of dispersion in interest rates across borrowers; see Baneriee and Duflo (2005, 2010) and references therein for details.
} 


\subsection{Gross vs. Value-Added Output and the Role of Material Inputs}

The accounting framework described above applies to value-added output and ignores the role of material inputs in the production process, which in the manufacturing sector account for about one-half of gross output. A common assumption in the production function literature (e.g., Basu (1996)) is that material inputs and value-added output enter the gross-output production function in a Leontief form:

$$
\tilde{Y}_{i}=\min \left\{\frac{Y_{i}}{\theta_{y}}, \frac{M_{i}}{\theta_{m}}\right\}
$$

where $\tilde{Y}_{i}$ denotes gross output, $Y_{i}$ is value-added output, and $M_{i}$ is the quantity of materials input, while $\theta_{y}$ and $\theta_{m}$ capture the gross shares of value-added output and materials in production, respectively. In this case, the profit function is given by

$$
\Pi_{i}=\min \left\{\frac{Y_{i}}{\theta_{y}}, \frac{M_{i}}{\theta_{m}}\right\}-\left(r_{i}+\delta\right) K_{i}-\left(1+r_{i}\right) W L_{i}-\left(1+r_{i}^{m}\right) P_{m} M_{i}
$$

where $P_{m}$ denotes the price of the materials input and $r_{i}^{m}$ is the corresponding financing cost.

Given the Leontief production structure, optimality requires that $M_{i}=\frac{\theta_{m}}{\theta_{y}} Y_{i}$. The optimal choices of capital and labor are now modified to include the cost of material inputs in the production process:

$$
\begin{aligned}
(1-\alpha) \eta \frac{Y_{i}}{K_{i}} & =\frac{r_{i}+\delta}{\frac{1}{\theta_{y}}-\left[\frac{\theta_{m} P_{m}}{\theta_{y}}\right]\left(1+r_{i}^{m}\right)} \\
\alpha \eta \frac{Y_{i}}{L_{i}} & =\frac{\left(1+r_{i}\right) W}{\frac{1}{\theta_{y}}-\left[\frac{\theta_{m} P_{m}}{\theta_{y}}\right]\left(1+r_{i}^{m}\right)}
\end{aligned}
$$

First, consider a situation in which the financing cost of the materials input is zero - that is, $r_{i}^{m}=0$. In that case, the presence of the materials input in the production process only rescales costs associated with capital and labor inputs and does not affect the dispersion of the two revenue products. Hence, it has no implications for the measured TFP loss. Furthermore, gross output is proportional to its value-added counterpart, and our TFP accounting procedure is valid for either measure of output.

Alternatively, suppose $r_{i}^{m}=r_{i}$, so that the financing cost of the materials input is the same as that of capital and labor inputs. In this case, we need to modify the wedges to account for the additional financing costs. Specifically, the presence of the materials input in the production process will increase the dispersion of the wedges for a given dispersion in $r_{i}$. With $P_{m}=1$, the share of materials in gross output of one-half implies that $\theta_{y}=\theta_{m}=0.5$. Then, the cost of capital is $\left(\frac{r_{i}+\delta}{1-r_{i}}\right)$ and the cost of labor is $\left(\frac{1+r_{i}}{1-r_{i}}\right) W$. Following the procedure outlined above, and ignoring terms involving $r^{2}$, the first-order approximations of the $\log$-wedges around $\log \left(r_{i}\right)$ are now given 
Table 4: TFP Losses due to Resource Misallocation (Alternative Production Structures)

\begin{tabular}{lcc}
\hline \hline Capital Share $(1-\alpha)$ & $(1)$ & $(2)$ \\
\hline $1-\alpha=1 / 6$ & 0.73 & 1.26 \\
$1-\alpha=1 / 3$ & 1.76 & 2.55 \\
$1-\alpha=1 / 2$ & 3.16 & 4.19 \\
\hline \hline
\end{tabular}

Note: The implied TFP losses are in percent and are computed using the second-order log-normal approximation. Column 1 reports TFP losses under the assumption that financial frictions distort both the labor and capital inputs but not the materials input. Column 2 reports TFP losses assuming that the materials input is combined with value-added output in a Leontief production function to determine gross output.

by

$$
\begin{aligned}
\log w_{i}^{l} & \approx-\frac{1}{1-\eta}\left[2(1-(1-\alpha) \eta) r+\alpha \eta\left(\frac{r+\delta r}{r+\delta-\delta r}\right)\right] \log \left(r_{i}\right) \\
\log w_{i}^{k} & \approx-\frac{1}{1-\eta}\left[2 \alpha \eta r+(1-\alpha \eta)\left(\frac{r+\delta r}{r+\delta-\delta r}\right)\right] \log \left(r_{i}\right) .
\end{aligned}
$$

Because $\delta r$ is close to zero, the need to finance the materials input has a negligible effect on the dispersion of wedges through its effect on the cost of capital. By contrast, it does roughly double the dispersion of the labor wedge by increasing the dispersion in the cost of labor input.

As an alternative to the Leontief production technology, suppose that the materials input is substitutable with both labor and capital. Assuming a Cobb-Douglas production function, let $L_{i}$ denote a composite labor-materials input bundle that must be financed at the cost of $\left(1+r_{i}\right) W$. We may then interpret $Y_{i}$ as gross output and modify the capital share to reflect a gross-output production function. If the materials input share of gross output is $1 / 2$ and the capital share of value added is $1 / 3$, this implies that the capital share of gross output is $1 / 6$. Thus to allow for the materials input in a Cobb-Douglas production technology, it is sufficient to use the accounting procedure outlined in Section 2 but lower the capital share appropriately.

Table 4 reports the effect of allowing the materials input to enter the gross-output production function in a Leontief form and the effect of varying the capital share on the second-order approximation to the loss function. Column 1 reports the TFP loss associated with the baseline model, a case in which the labor and capital input choices are distorted by financial frictions. Column 2 reports the TFP loss in the case where financial frictions also distort the choice of the materials input. For each of these alternative production structures, we consider capital shares of $1 / 6,1 / 3$, and $1 / 2$.

Assuming that gross output is a Leontief function of value-added output and the materials input, the implied TFP losses increase - relative to the baseline case in which financial frictions apply only to the capital and labor inputs - when we allow for financial frictions to influence the 
choice of the materials input. The increase in the TFP loss, however, is modest. In particular, when $1-\alpha=1 / 3$, a case that is most relevant in that comparison, the relative TFP loss increases from 1.76 percent to 2.55 percent.

To understand the effect of substitutability of inputs on the TFP losses, one should compare the baseline model (Column 1) with $1-\alpha=1 / 6$ to the model with the materials input (Column 2) with $1-\alpha=1 / 3$. The baseline model with $1-\alpha=1 / 6$ can be interpreted as a production structure where gross output depends on capital, labor, and materials within a Cobb-Douglas production function. The model with the materials input and $1-\alpha=1 / 3$, in contrast, can be interpreted as a production structure where value-added output is a Cobb-Douglas function of labor and capital, and the materials input enters the gross-output production function in a Leontief form. Switching from unit elasticity to no substitutability for the materials input increases the TFP loss from 0.73 percent to 2.55 percent. It is important to remember that the cost of capital is more sensitive to variation in interest rates than the cost of labor and material inputs. Reducing the substitutability between capital and other inputs magnifies the importance of financial friction on capital input choices and increases the overall TFP loss. Nonetheless, these effects appear to be relatively modest even if one completely eliminates any form of substitutability between value-added output and the materials input.

Overall, these results imply that our finding that dispersion in borrowing costs across firms results in relatively modest TFP losses is robust to alternative assumptions regarding the production structure and the various input financing choices. In general, TFP losses are highest in situations where the capital share is high, substitutability among inputs is low, and financial frictions apply to all inputs.

\subsection{Comparison with Hsieh-Klenow Methodology}

As noted in the introduction, the methodology proposed by Hsieh and Klenow (2009) implies sizable TFP losses for the U.S. manufacturing sector due to misallocation. Their methodology relies on measured dispersion in marginal revenue products of labor and capital, though they recognize that plant-based marginal revenue products may contain substantial measurement error; indeed, they argue against interpreting the implied TFP losses for the U.S. manufacturing sector as evidence for resource misallocation. Although our data set contains manufacturing firms rather than plants and does not include labor input choices, we can nonetheless gauge the implications of applying their methodology to our data set by comparing the dispersion in the marginal revenue product of capital - as measured by the sales-to-capital ratio - to the dispersion in the cost of capital as measured by firm-specific interest rates. More specifically, the implied dispersion in the cost of capital can be inferred directly from the measured dispersion in the log of the sales-to-capital ratio.

Table 5 reports the dispersion in the log of the sales-to-capital ratio and the log of the cost of capital as measured by $\log \left(r_{i t}+\delta\right)$. The first row reports the overall standard deviation, while 
Table 5: Comparison of Dispersion Measures

\begin{tabular}{lccc}
\hline \hline & \multicolumn{2}{c}{ Std. Deviation } \\
\cline { 2 - 3 } Dispersion Measure & $\log \left(r_{i t}+\delta\right)$ & $\log \left(S_{i t} / K_{i, t-1}\right)$ & Ratio $^{\mathrm{a}}$ \\
\hline Overall & 0.149 & 0.690 & 4.629 \\
Industry adjusted & 0.144 & 0.565 & 3.911 \\
Long-run/industry adjusted & 0.126 & 0.574 & 4.540 \\
\hline \hline
\end{tabular}

Note: Sample period: 1985:Q1-2010:Q4; No. of firms = 496; Obs. =16,975. Overall standard deviations are computed using raw data on $\log \left(r_{i t}+\delta\right)$ and $\log \left(S_{i t} / K_{i, t-1}\right)$; industry-adjusted standard deviations remove industry (3-digit NAICS) fixed effects from both measures; and long-run/industry-adjusted standard deviations remove industry fixed effects from firm-specific means of $\log \left(r_{i t}+\delta\right)$ and $\log \left(S_{i t} / K_{i, t-1}\right)$. In all cases, we assume the depreciation rate $\delta=0.06$.

a The ratio of $\operatorname{STD}\left[\log \left(r_{i t}+\delta\right)\right]$ to $\operatorname{STD}\left[\log \left(S_{i t} / K_{i, t-1}\right)\right]$.

the second row accounts for heterogeneity at the industry (3-digit NAICS) level by first removing industry means from both variables. By construction, these two measures allow for variation across firms and time. To focus on long-run differences, the third row first computes the firm-specific means of both measures and then computes the standard deviation of these long-run firm averages relative to their industry means.

The results reported in the table indicate a much greater implied dispersion when the log of the sales-to-capital ratio is used as a proxy for the user cost of capital, compared with the dispersion based on observed interest rates. Depending on how one corrects for the inter-industry and withinfirm variation, we obtain dispersion measures based on measured marginal revenue products that are about four times greater than those obtained using the cost of capital computed using observed firmspecific interest rates. Focusing on the long-run measure, which likely captures the true average cost of capital most accurately, these results imply that the Hsieh-Klenow methodology may significantly overstate the TFP losses due to misallocation relative to the user-cost methodology in our data set, provided that the misallocation mechanism is driven primarily by distortions in financial markets.

\subsection{Time-Series Variation in Interest Rate Dispersion}

A number of recent papers (Gilchrist, Sim, and Zakrajšek (2011), Khan and Thomas (2011), and Arellano, Bai, and Kehoe (2012)) study the implications of increased dispersion in profitability on resource allocation in macroeconomic models with various forms of financial market frictions. As the severity of financial frictions increases, these models generally predict a greater dispersion of financial outcomes across heterogeneous firms; for example, firms with low leverage and high cash holdings can continue to borrow at relatively low cost, whereas those with high leverage and low cash holdings can begin to face prohibitive borrowing costs during periods of financial turmoil.

To explore time variation in the dispersion of interest rates, the solid lines in Figure [6 show the cross-sectional standard deviation of $\log \left(r_{i t}\right)$ over time and the quarterly growth rate of the cyclically-adjusted total factor productivity as constructed by Basu, Fernald, and Kimball (2006). 
Figure 6: Dispersion of Interest Rates and the Growth of TFP

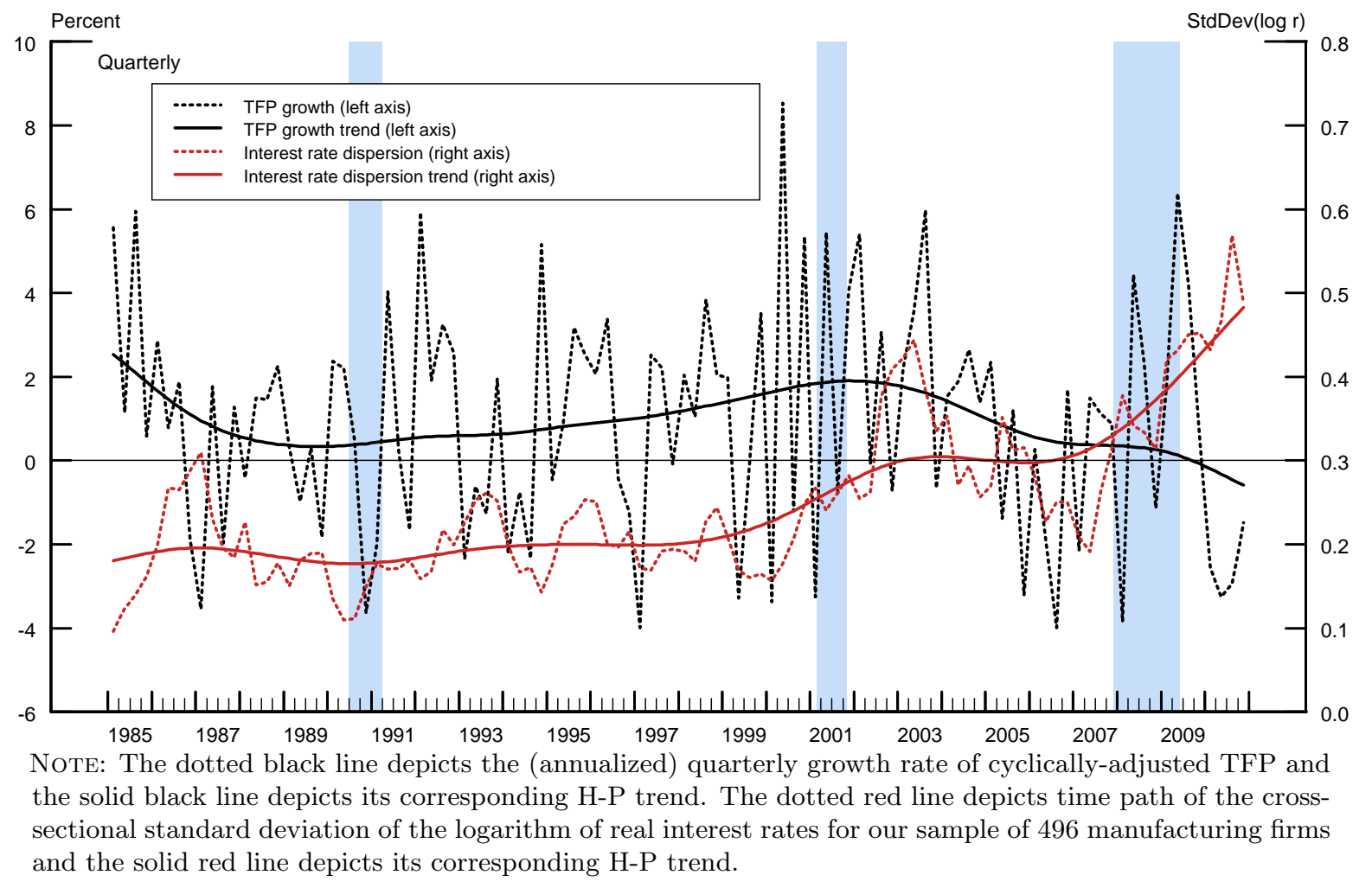

To abstract from fluctuations at business cycle frequencies, the dotted lines show the two series deviated from their respective local means using the Hodrick and Prescott (1997) (H-P) filter with $\lambda=1,600$. According to the figure, the dispersion in real interest rates in U.S. manufacturing was relatively low for the first decade or so of our sample period. In the late 1990s, however, the dispersion of interest rates started to edge higher, increasing steadily through the 2001 economic downturn and the aftermath of the bursting of the dot-com bubble. After leveling off in the mid2000 s, interest rate dispersion again started to trend higher in 2007, increasing appreciably over the remainder of the sample period.

As the dispersion in interest rates increased in the post-2000 period, the trend growth of TFP also slowed notably. Although one cannot assign causality to these developments on the basis of a simple correlation, this comovement is consistent with the notion that financial distortions reflecting the past two finance-driven cyclical downturns have increased the misallocation of resources in the economy and thereby reduced the pace of TFP growth. Given our calibration, the increase in the trend dispersion of interest rates since the start of the 2007 recession can account for about 25 basis points of the step-down in the annual TFP growth, assuming that financial frictions apply to both labor and capital inputs. Clearly, this represents a non-trivial portion of the overall slowdown in 
trend TFP growth that has materialized during this time period.

\section{Conclusion}

This paper develops a tractable TFP accounting framework that is used to compute the resource loss due the misallocation of inputs in the presence of financial market frictions. To a second-order approximation, our methodology implies that resource losses may be inferred directly from the dispersion in borrowing costs across firms. Using a direct measure of firm-specific borrowing costs, we show that for a subset of U.S. manufacturing firms, the resource loss due to such misallocation is relatively small-between 1.5 and 3.5 percent of measured TFP. On the whole, our results are consistent with those of Midrigan and Xu (2010) and Hopenvahn (2011), who argue that financial market frictions are unlikely to imply large efficiency losses in an economy with relatively efficient capital markets.

It is important, however, to acknowledge several caveats to our methodology. First, to the extent that firms experience direct credit rationing, the variation in observed interest rates understates the true variation in the cost of capital. For our sample of publicly-traded manufacturing firms, direct credit rationing seems rather implausible. Nonetheless, when measuring borrowing costs for smaller firms in the U.S. economy or firms in developing countries, credit rationing may be of real concern. Thus, while one might not directly observe the dispersion of interest rates that is ten times greater than that observed in the U.S. financial data, credit rationing would certainly imply greater dispersion in the shadow value of financial resources.

In addition, our accounting framework abstracts from the entry and exit of firms, along with the potential selection effects that financial distortions may induce on those margins. In the United States, however, incumbent firms account for the overwhelming share of economic activity, so such selection effects are unlikely to be important - nevertheless, they may be of concern in developing economies. Moreover, distortions in credit markets may influence the decision to employ one's human capital in an entrepreneurial capacity, a source of resource misallocation that can have significant consequences for aggregate TFP, according to the recent work of Buera, Kaboski, and Shin (2011).

Subject to these caveats, a clear advantage of our methodology is that it can easily be used to study the question of what portion of the differences in TFP across countries may be attributable to the misallocation of inputs arising from financial market frictions. Counterfactual experiments indicate that a ten-fold increase in the dispersion in interest rates across firms implies a reductionthrough the effect of borrowing costs on resource allocation - in measured TFP of about 20 percent. This finding implies that the dispersion in borrowing costs in developing countries must be an order of magnitude greater than the dispersion of borrowing costs in the United States in order for financial distortions to account for a significant share of the TFP differentials between developed and developing economies. 
Moreover, it is well known that even in advanced economies such as the United States, there is considerable dispersion in the observed marginal product of capital across production units. To the extent that the dispersion in marginal products is not a result of measurement error, this implies that the U.S. economy would realize significant productivity gains in response to optimal resource allocation. However, the observed dispersion in the marginal product of capital in our data is four times greater than the dispersion in the user cost of capital as measured by the firm-specific interest rates. This divergence suggests that assigning all of the observed dispersion in factor input choices to credit market distortions would substantially overstate the effect of financial frictions on resource misallocation.

\section{References}

Amaral, P. S., And E. Quintin (2010): "Limited Enforcement, Financial Intermediation, and Economic Development," International Economic Review, 51(3), 785-811.

Arellano, C., Y. Bai, and P. J. Kehoe (2012): "Financial Markets and Fluctuations in Volatility," Staff Report No. 466, Federal Reserve Bank of Minneapolis.

Banerjee, A. V., and E. Duflo (2005): "Growth Theory Through the Lens of Development Economics," in Handbook of Economic Growth, ed. by S. N. Durlauf, and P. Aghion, vol. 1A, pp. 473-522. Elsevier Science Publishers, Amsterdam.

— (2010): "Giving Credit Where It is Due," Journal of Economic Perspectives, 24(3), 61-80.

BAsu, S. (1996): "Procyclical Productivity: Increasing Returns or Cyclical Utilization," Quarterly Journal of Economics, 111(3), 719-751.

Basu, S., J. G. Fernald, and M. S. Kimball (2006): "Are Technology Improvements Contractionary?," American Economic Review, 96(5), 1418-1448.

Bharath, S. T., and T. Shumway (2008): "Forecasting Default with the Merton Distance to Default Model," Review of Financial Studies, 21(3), 1339-1369.

Buera, F. J., J. P. Kaboski, and Y. Shin (2011): "Finance and Development: A Tale of Two Sectors," American Economic Review, 101(5), 1964-2002.

Collin-Dufresne, P., R. S. Goldstein, and J. S. Martin (2001): "The Determinants of Credit Spread Changes," Journal of Finance, 56(6), 2177-2207.

Driessen, J. (2005): "Is Default Event Risk Priced in Corporate Bonds?," Review of Financial Studies, 18(1), 165-195.

Duffie, D., L. Saita, and K. Wang (2007): "Multi-Period Corporate Default Prediction with Stochastic Covariates," Journal of Financial Economics, 83(3), 635-665.

Elton, E. J., M. J. Gruber, D. Agrawal, and C. Mann (2001): "Explaining the Rate Spread on Corporate Bonds," Journal of Finance, 56(1), 247-277. 
Gilchrist, S., J. W. Sim, and E. ZakrajŠEK (2011): "Uncertainty, Financial Frictions, and Investment Dynamics," Working Paper, Dept. of Economics, Boston University.

Gilchrist, S., V. YAnkov, And E. ZakrajŠEK (2009): "Credit Market Shocks and Economic Fluctuations: Evidence From Corporate Bond and Stock Markets," Journal of Monetary Economics, 56(4), 471-493.

Gilchrist, S., And E. ZakrajŠEK (2007): "Investment and the Cost of Capital: New Evidence from the Corporate Bond Market," NBER Working Paper No. 13174.

(2012): "Credit Spreads and Business Cycle Fluctuations," American Economic Review, 102(4), 1692-1720.

Greenwood, J., J. M. Sanchez, and C. Wang (2010): "Financing Development: The Role of Information Costs," American Economic Review, 100(4), 1975-1891.

Greenwood, J., J. M. Sanchez, and C. Wang (2012): "Quantifying the Impact of Financial Development on Economic Development," Forthcoming Review of Economic Dynamics. Available at http://dx.doi.org/10.1016/j.red.2012.07.003.

Guner, N., G. Ventura, and Y. Xu (2008): "Macroeconomic Implications of Size-Dependent Policies," Review of Economic Dynamics, 11(4), 721-744.

Hakansson, N. H. (1982): "Changes in the Financial Market: Welfare and Price Effects and the Basic Theorems of Value Conservation," Journal of Finance, 37(4), 977-1004.

Hall, R. E., And C. I. Jones (1999): "Why Do Some Countries Produce So Much More Output per Worker than Others?," Quarterly Journal of Economics, 114(1), 83-116.

Hodrick, R. J., And E. C. Prescott (1997): "Postwar U.S. Business Cycles: An Empirical Investigation," Journal of Money, Credit, and Banking, 29(1), 1-16.

Hopenhayn, H. A., and R. Rogerson (1993): "Job Turnover and Policy Evaluation: A General Equilibrium Analysis," Journal of Political Economy, 101(5), 915-938.

Hopenyahn, H. A. (2011): "Firm Microstructure and Aggregate Productivity," Journal of Money, Credit, and Banking, 43(5), 111-145.

Hotchisiss, E. S., And T. Ronen (2002): "The Informational Efficiency of the Corporate Bond Market: An Intraday Analysis," Review of Financial Studies, 15(5), 1325-1354.

Houwelling, P., A. Mentink, and T. Vorst (2005): "Comparing Possible Proxies of Corporate Bond Liquidity," Journal of Banking and Finance, 29(6), 1331-1358.

Hsieh, C.-T., And P. J. Klenow (2009): "Misallocation and Manufacturing TFP in China and India," Quarterly Journal of Economics, 124(4), 1403-1448.

Khan, A., And J. K. Thomas (2011): "Credit Shocks and Aggregate Fluctuations in an Economy with Production Heterogeneity," Working Paper, Dept. of Economics, The Ohio State University. 
Klenow, P. J., and A. Rodríguez-Clare (1997): "The Neoclassical Revival in Growth Economies: Has it Gone Too Far?," in NBER Macroeconomics Annual, ed. by B. S. Bernanke, and J. J. Rotemberg, pp. 73-102. The MIT Press, Cambridge.

Lucas, R. E. (1978): "On the Size Distribution of Business Firms," Bell Journal of Economics, $9(2), 508-523$.

Matsuyama, K. (2007): "Aggregate Implications of Credit Market Imperfections," in NBER Macroeconomics Annual, ed. by D. Acemoglu, K. Rogoff, and M. Woodford, pp. 1-60. The MIT Press, Cambridge.

Merton, R. C. (1974): "On the Pricing of Corporate Debt: The Risk Structure of Interest Rates," Journal of Finance, 29(2), 449-470.

Midrigan, V., AND D. Xu (2010): "Finance and Misallocation: Evidence From Plant-Level Data," Working Paper, Dept. of Economics, New York University.

Restuccia, D., and R. Rogerson (2008): "Policy Distortions and Aggregate Productivity with Heterogeneous Plants," Review of Economic Dynamics, 11(4), 707-720.

Schaefer, S. M., and I. A. Strebulaev (2008): "Structural Models of Credit Risk are Useful: Evidence from Hedge Ratios on Corporate Bonds," Journal of Financial Economics, 90(1), 1-19. 